\title{
Climate policy confidence indicator: final report to CCCEP
}

Will McDowall, Dimitri Zenghelis and Paul

Drummond

March 2016

Centre for Climate Change Economics and Policy Working Paper No. 261

Grantham Research Institute on Climate Change and the Environment Working Paper No. 231 
The Centre for Climate Change Economics and Policy (CCCEP) was established by the University of Leeds and the London School of Economics and Political Science in 2008 to advance public and private action on climate change through innovative, rigorous research. The Centre is funded by the UK Economic and Social Research Council. Its second phase started in 2013 and there are five integrated research themes:

1. Understanding green growth and climate-compatible development

2. Advancing climate finance and investment

3. Evaluating the performance of climate policies

4. Managing climate risks and uncertainties and strengthening climate services

5. Enabling rapid transitions in mitigation and adaptation

More information about the Centre for Climate Change Economics and Policy can be found at: http://www.cccep.ac.uk.

The Grantham Research Institute on Climate Change and the Environment was established by the London School of Economics and Political Science in 2008 to bring together international expertise on economics, finance, geography, the environment, international development and political economy to create a worldleading centre for policy-relevant research and training. The Institute is funded by the Grantham Foundation for the Protection of the Environment and the Global Green Growth Institute. It has nine research programmes:

1. Adaptation and development

2. Carbon trading and finance

3. Ecosystems, resources and the natural environment

4. Energy, technology and trade

5. Future generations and social justice

6. Growth and the economy

7. International environmental negotiations

8. Modelling and decision making

9. Private sector adaptation, risk and insurance

More information about the Grantham Research Institute on Climate Change and the Environment can be found at: http://www.Ise.ac.uk/grantham.

This working paper is intended to stimulate discussion within the research community and among users of research, and its content may have been submitted for publication in academic journals. It has been reviewed by at least one internal referee before publication. The views expressed in this paper represent those of the author(s) and do not necessarily represent those of the host institutions or funders. 


\section{Climate Policy Confidence Indicator: Final Report to CCCEP}

March 2016

Will McDowall*, Dimitri Zenghelis** and Paul Drummond*

*UCL Institute for Sustainable Resources

**Grantham Research Institute on Climate Change and the Environment and ESRC Centre for Climate Change Economics and Policy, LSE

This research was funded by the Policy Innovation Fund of the ESRC Centre for Climate Change Economics and Policy (CCCEP)

\section{Introduction}

The CCCEP Policy Innovation fund supported a project to explore the feasibility and perceived usefulness of an indicator of confidence in climate change policies. This final report presents the analysis that was undertaken by the project team, the outcomes of a workshop, and highlights ongoing steps to further develop the work.

A stakeholder workshop was held to inform the proposed indicator. This took place on November $18^{\text {th }} 2015$ at UCL (see the annexes for a list of participants, and for the slides presented at the workshop by the project team). Prior to the workshop, a discussion paper was developed and circulated to participants.

This report first provides the background and rationale of the idea itself, and examines why an indicator of confidence in policy might be useful. Section 3 then examines key issues relating to the scope and focus of such an indicator, and illustrates the views of stakeholders that participated in the project workshop on these issues. Sections 4 and 5 examine existing attempts or methods for measuring confidence or policy uncertainty in climate and energy fields, and in other related fields, and draws lessons for how a better climate policy confidence indicator might be developed. A summary of the methodological options for developing an indicator is presented in section 6 , while section 7 draws conclusions and highlights next steps. Throughout the report, the perspectives of stakeholders consulted during the workshop are provided in text boxes.

\section{Background: why might an indicator of policy certainty be valuable?}

Policy 'certainty' (or at least, 'credibility') is widely identified as an important factor in transitioning cost-effectively to a green, low-carbon economy. The idea is that credibility of and confidence in climate policy raise perceptions of the market opportunities associated with low-carbon goods and services and reduce the risk of investment into what may become stranded assets, thus focusing innovator and entrepreneur effort on developing and deploying such goods and services. 
Correspondingly, confidence is also assumed to lower risk premiums for low-carbon investments, thus reducing the costs of decarbonisation.

In economic management both consumer confidence and business confidence are widely used as 'leading indicators'. They are typically collected not by governments, but by consulting firms or polling firms. They are widely reported, and are used as inputs into a wide range of economic analysis. However, we do not have indicators for levels of business or investor confidence in the 'direction of travel' for decarbonisation, in terms of both the policy framework and political commitment required to introduce, maintain and strengthen it. Having and monitoring this data would be valuable - one could track sentiment over time, and ideally compare it across geographies and jurisdictions. With a robust long-term dataset, econometric studies could be produced examining the importance of policy credibility in low-carbon investment (in both innovation and deployment). Politically, the data would also reveal when and how governments are failing to bolster credibility in long-term policy objectives. If confidence in political commitment to decarbonisation is sliding, the construction and publication of an indicator that measures this could help maintain pressure on politicians to reverse this trend.

One might expect such an indicator to be able to 'pick up' key policy-related moments that have been seen in hindsight as having had an important impact on expectations and perceptions on the direction of travel. Examples include the 2008 US Presidential Election, the 2009 failure of the Copenhagen conference, and some key national or regional policy choices, like the Canadian withdrawal from Kyoto or major EU ETS decisions.

\section{Scope and Focus}

Broadly, the indicator would aim to identify and measure confidence in decarbonisation commitment and policy. This would not be specific to any particular policy instrument, but instead concerns the general perception of how seriously policy makers and politicians are taking the decarbonisation agenda, and how well the policy framework is, and is likely to, encourage the investments and behaviours required. Indeed, it should be made clear that the intention of the indicator would not be simply to measure confidence in the 'stability' of the policy framework and political commitment. Whilst this is an important contributor to confidence, taken alone, it is not sufficient. For example, a policy framework may be fully stable over a given timeframe, but the incentives and facilitation it provides may be wholly inadequate.

The development of an indicator would have three aims:

a) Informing the political goal, to identify and publicise when confidence is being undermined (and/or bolstered), in order to help politicians to understand when their words or actions undermine confidence in climate policy, and to promote good practice.

b) Informing research focusing on the determinants of confidence

c) Informing research focusing on the impact of confidence on other variables

The balance between these aims will help inform some of the choices below, and will be informed by stakeholder engagement through the workshop. The subsequent sections aim to initiate some discussion surrounding how such an indicator may be defined and developed. Answers to some of the discussion points raised below would depend on what would be most useful - i.e. they are choices that can be informed by stakeholder interests and needs. 


\section{Insights from the stakeholder workshop}

Participants were first invited to provide their reflections on the objectives and the overall definitions used in the discussion paper. Participants expressed their interest in the proposed indicator, and in particular viewed the 'political' objective (in which the value of the indicator is principally the role that it can play in informing political debate) as potentially the most valuable. However, the project team were advised to re-frame the way in which they communicated this, moving away from more confrontational language ("holding politicians to account" in the original discussion paper) to more positive language ("promote good practice"). Participants described the indicator as a potential "accelerator of change", and believed that it would fill a gap in the current policy debate.

It was also noted that while advocacy organisations would be most directly interested in the political use of such an indicator, they also relied on research that highlights the importance of confidence in driving activities in the 'real economy'. This highlights the value of the research objectives identified in the discussion paper (i.e. that data on policy confidence would enable research on the importance of confidence in the real economy). It was noted that the value of a policy confidence indicator in the policy debate is greatly enhanced where there is good evidence on the relationship between confidence and key variables of interest to policy and investment, in particular: cost of borrowing, share prices and investment levels.

It was noted that there may be interest from investors, in particular if the indicator captures confidence across countries. It was less clear whether there may be an appetite for corporate contributions to the funding of the indicator, but this is an avenue that should be explored. Participants noted that expert groups of asset managers, such as the International Investor Group for Climate Change, would be a highly relevant and expert stakeholder.

\subsection{What Constitutes 'Climate Policy'?}

To measure confidence in the direction of 'climate policy', such a term must first be defined. As may be clear from above, the focus is on GHG emission mitigation only (particularly $\mathrm{CO}_{2}$ ). Political commitment and policies to encourage adaptation actions are not considered. However, producing a precise definition of what comprises 'climate policy', even within these constraints, remains difficult. Whilst direct actions such as explicit carbon pricing would clearly be considered 'climate policy', many instruments influence emission trends indirectly (such as instruments to encourage energy efficiency, or to reduce vehicle congestion), and may or may not hold emission reduction as an explicit objective (of varying priority). Yet other instruments may induce such effects largely (or purely) coincidentally against their intended objectives (an effect which may or may not be expected). An example may be changes to spatial planning regulations or procedures or policies to encourage more efficient use of energy.

For the purposes of this report, 'climate policy' is broadly defined as any policy action that explicitly seeks, as a primary or other objective, to require, encourage or facilitate investment in the development or deployment of low(er)-carbon technologies or behaviours.

\subsection{Sectoral Scope}

Climate policy may impact, directly or indirectly, all sectors and actors within the economy. Ideally, an indicator to assess confidence in climate policy would therefore take into account the views held by all groups of actors in the market, to produce a comprehensive picture. However, there are clear 
issues with this - not least logistical and practical. Even if such an inclusive indicator were possible, it would only be useful if those surveyed were aware of the climate policy framework and political intentions. This issue is exemplified in the one-off Ipsos MORI Climate Change Confidence Index survey conducted in the UK in 2007. The survey asked representative sample of 964 adults how confident they were that different groups, including the British Government and international leaders, would take the action needed to tackle climate change ${ }^{1}$. Responses to such question may be greatly influenced by beliefs and knowledge surrounding the scale of the challenge, options available to meet it (both individual actions and policy actions), and what is already being done (e.g. the existing policy framework). Figure 1 illustrates the results of this survey.

Figure 1 - Ipsos MORI 2007 Climate Change Confidence Index

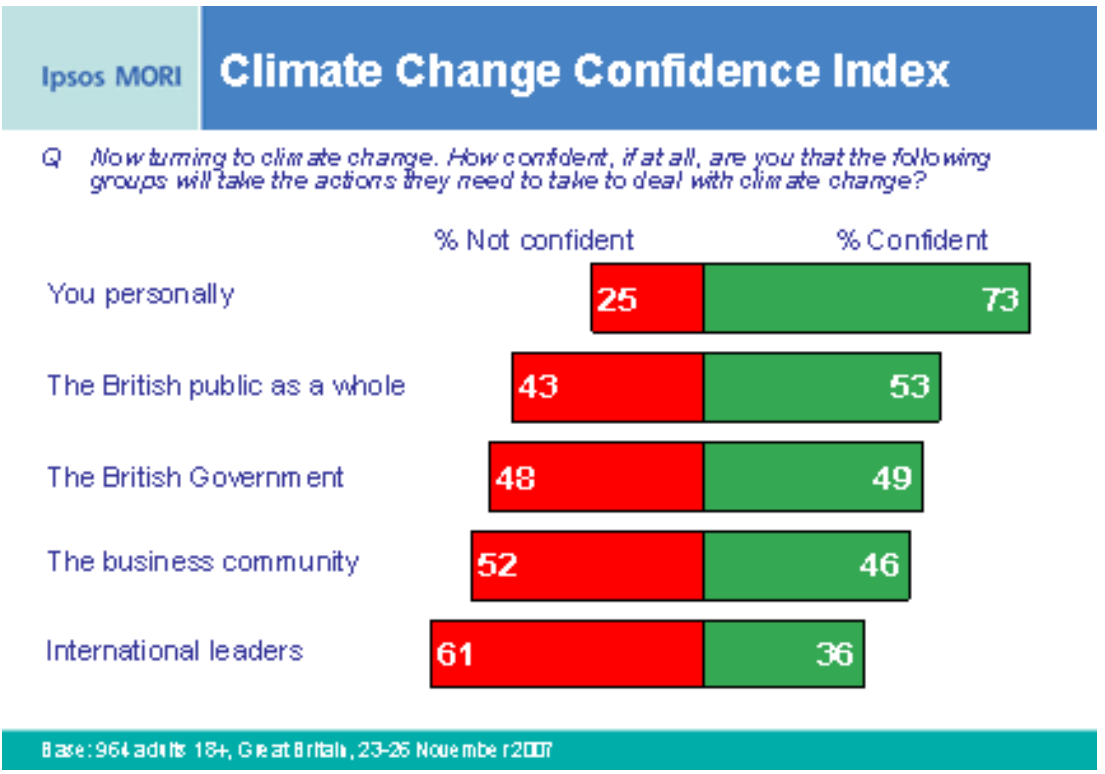

It does not appear as if there are any existing indicators or surveys examining awareness of climate policy (at any geographic scale or jurisdiction). The majority of indicators appear to centre on awareness of the climate change issue itself, and levels of concern or desire for action to be taken. Examples include the HSBC Climate Confidence Monitor, an annual survey that ran for three years (2006-2009) over twelve countries, examining importance of action on climate change to the general public ${ }^{2}$, and the DECC Public Attitudes Tracking Survey, which conducts an annual public survey in the UK on opinions on climate change (from 2012 onwards), including 'what is the biggest challenge facing Britain?' (with 'climate change' as an option), and 'What's causing climate change?' (with 'natural processes', 'human activity' and 'partly natural, partly human' as options). It also asks questions regarding support for renewables, nuclear and shale gas extraction, among other related issues ${ }^{3}$.

If an indicator for confidence in climate policy were to be based on awareness of climate policy in the first place, a more targeted approach would likely be required. As no existing indicators of such awareness can guide this, this may focus may be, at least initially, on actors, groups and sectors that are already directly subject to climate policy instruments, and whose operations may be relatively significantly influenced by their presence. Awareness of at least part of the policy framework amongst these groups is therefore likely to be high. In the EU this may include, for example,

\footnotetext{
${ }^{1}$ https://www.ipsos-mori.com/researchpublications/researcharchive/172/Public-Not-Confident-That-InternationalLeaders-Can-Reach-Climate-Deal.aspx

${ }^{2}$ http://www.theclimategroup.org/what-we-do/news-and-blogs/hsbc-climate-confidence-monitor-65-of-globalpopulation-demand-a-global-deal/

${ }^{3}$ https://www.gov.uk/government/collections/public-attitudes-tracking-survey
} 
participants in the EU ETS (power sector and heavy industry), and the construction industry and vehicle manufacturers (for which both of which are subject to minimum energy or $\mathrm{CO}_{2}$ performance standards for their products $\left.{ }^{4}\right)$. At the UK level, for example, this may also be extended to participants in the CRC Energy Efficiency Scheme (CRC), and perhaps the Climate Change Levy (CCL). However, such an approach excludes other key sectors and actors, such as individual homeowners (of existing buildings), and other (potential) investors and providers of finance for low-carbon technologies and infrastructure (e.g. banks and institutional investors).

An alternative solution may be to determine confidence in climate policy amongst or concerning the sectors that supply low-carbon goods and services. In March 2015, the UK Department for Business, Innovation and Skills (BIS) released a report on 'The Size and Performance of the UK Low Carbon Economy', along with a definition of which the 24 sectors and 6 groupings that constituted the lowcarbon economy (illustrated in Table 1).

Table 1 - Low Carbon Sectors and Groups

\begin{tabular}{|c|c|}
\hline Grouping & Sectors \\
\hline Low-Carbon Electricity & $\begin{array}{c}\text { Onshore wind } \\
\text { Offshore Wind } \\
\text { Nuclear Energy } \\
\text { Hydroelectric Energy } \\
\text { Marine Energy } \\
\text { Solar Photovoltaic (PV) } \\
\text { Carbon Capture and Storage }\end{array}$ \\
\hline Low-Carbon Heat & $\begin{array}{c}\text { Geothermal Heat } \\
\text { Heat Pumps } \\
\text { Solar Thermal } \\
\text { Heat Networks }\end{array}$ \\
\hline Waste Processing, Energy from Waste and Biomass & $\begin{array}{c}\text { Recycling - Recovery and Reprocessing of } \\
\text { Materials from Waste } \\
\text { Generation of Energy from Waste and } \\
\text { Biomass } \\
\text { Alternative Fuels } \\
\text { Biomass Equipment }\end{array}$ \\
\hline Energy Efficiency Products & $\begin{array}{c}\text { Energy-Efficient Lighting } \\
\text { Insulation } \\
\text { Energy-Efficient Windows and Doors } \\
\text { Heat Recovery and Ventilation } \\
\text { Energy Controls and Control Systems } \\
\text { Sustainable Architecture and Buildings }\end{array}$ \\
\hline Low-Carbon Services & $\begin{array}{l}\text { Low-Carbon Advisory } \\
\text { Low-Carbon Finance }\end{array}$ \\
\hline Other-Low Carbon & Low Emission Vehicles \\
\hline
\end{tabular}

Regardless of the actors and sectors directly or indirectly targeted by climate policy instruments or actions, the sectors listed in Table 1 will likely be impacted in one way or another. For example, some sectors, such as low-emission vehicles, are already directly subject to climate policy (as

\footnotetext{
${ }^{4}$ Principally by the Energy Performance of Buildings Directive (EPBD) (Directive 2010/31/EU) and the CO2 Intensity of Cars Regulation (Regulation 333/2014), respectively.

${ }^{5}$ https://www.gov.uk/government/uploads/system/uploads/attachment_data/file/416240/bis-15-206-size-andperformance-of-uk-low-carbon-economy.pdf
} 
discussed above). Others, however, will be influenced indirectly through changes in demand for their products or services (from renewable electricity technologies, or low-carbon advisory and finance). Each of these sectors are heavily influenced by the climate policy landscape and associated political commitment, and are therefore likely to be highly aware of and engaged with at least part of it. However, clearly identifying and delineating these sectors may prove challenging. For example, many firms in the sectors are not limited to low-carbon products and services (e.g. vehicle manufacturers).

\section{Insights from the stakeholder workshop}

In terms of sectors, it was widely agreed (though not unanimously) that it would not be worthwhile surveying the views of consumers/citizens, since the notion of confidence in policy requires some minimum level of knowledge about policy in this area. Consumer sentiment is not only a driver of household consumption but also the political responses to perceived voter preferences. It therefore can be expected to have a direct bearing on both investor and policymaker activity. Several participants suggested that it would be sufficient to focus on large firms, rather than 'all business', and in particular noted the importance of asset managers and asset owners, in addition to the groups of companies highlighted in the discussion paper.

\subsection{Geographic Scope}

Climate policy originates and is introduced at various levels of governance and geographic scope. Such levels may interact and influence each other, particularly with higher levels of governance influencing those below. For example, actual, expected or perceived progress (or a lack thereof) in international climate negotiations may influence actual or expected regional or national climate policy regimes. At the EU level, for example, actual or expected developments in climate policy may directly impact Member State. National level policy may then impact sub-national or city level policy, which may be more or less variable from the national policy landscape and political commitment depending on the level of authority and discretion sub-national authorities have. As such, confidence, action and expectation at one (higher) level of governance may impact such aspects of another.

Different market actors may be influenced by different and/or multiple levels of climate policy. For example, from an innovation and business opportunity perspective for international firms, perceptions of global decarbonisation policy maybe nearly as important as national policy. For some actors and investors, such as homeowners, local-level policy and political commitment may be of most relevance.

An indicator of policy confidence may include aspects from all relevant levels, depending on the sectoral definition taken and the specific purpose of the indicator. However, practical limitations may come into play, depending on how the indicator is constructed. Arguably, it is most likely that the focus will be at a national level, as this is often the governance level and jurisdiction that exhibits most control over the policy landscape, and where political commitment (or lack of) is most influential across all the relevant areas of policy. Additionally, any information and data that may be used to construct the indicators is most likely to be available at a national level, and it is the level of jurisdiction that may be most clearly defined if data is collected using a qualitative approach. 


\section{Insights from the stakeholder workshop}

There was general agreement that a national scope made most sense, though it was recognised that the national and global discussions on climate policy would inevitably complicate a neat division. It was suggested that it would be valuable to be able to 'zoom in/out', to understand how confidence differed among countries and globally.

\subsection{Temporal Scope}

Another key issue is that of time; over what timeframe is confidence in policy and political commitment most important? Is it more useful to have an indicator of confidence in the short- or long-term (however defined)? Different actors, and different investment and behavioural decisions by the same actors, are influenced by incentives and drivers across different timeframes. Whilst the purchase of a low-carbon vehicle or high-efficiency appliance may depend more on (relatively) shortterm policy drivers (e.g. subsidies), investment in the R\&D required to develop such products by manufacturers depend on a significant longer-term view (e.g. the presence of a legally-binding 2050 GHG reduction target in the UK, and associated 'carbon budgets'). However, accurately delineating the relative importance of different horizons (and their specific definition) is likely to be difficult.

One approach may be to attempt to determine confidence in climate policy over three broad time horizons. For example, 'short-term' (e.g. $<5$ years), 'medium-term' (5-9 years) and 'long-term' (>10 years). However, the relevance of an indicator for each of these time horizons would depend on the specific objective of the indicator, as discussed above.

\section{Insights from the stakeholder workshop}

At the workshop, there was general agreement that while both long-run and short-run confidence are important. Participants further agreed that it is confidence in policy direction over the coming five years that is the most relevant timescale. Confidence over other timescales (such as very long-term) would be desirable to measure, but less directly important.

\subsection{Periodicity}

The appropriate periodicity for construction and publication of the indicator will depend on the relative emphasis between the three core goals defined in Section 2.

a) The political goal, to identify and publicise when confidence is being undermined, may be best supported by frequent (monthly) releases. This would enable analysis of the impact of specific policy events (high profile speeches, policy announcements, treaties, etc.) on the confidence in climate policy and political commitment.

b) Research focusing on the determinants of confidence would be best supported by a relatively fine timescale of analysis, with perhaps monthly data available. As above, it allows for the potential identification of the impact of specific policy-related events.

c) Research focusing on the impact of confidence on other variables might require a less frequent publication, since those other variables are unlikely to be available at intervals of less than once per quarter, and many are annual. 


\section{Insights from the stakeholder workshop}

For the periodicity, a quarterly publication was seen as a useful balance between the desire to have relatively frequent updates and the difficulty of collecting the data frequently. It was noted that a frequent publication would almost certainly undermine the response rate of a survey, as respondents would be over-burdened. However, it was also noted that frequent publication would allow, for example, monitoring of confidence pre- and post-budget announcements, or around other significant policy events. Periodicity was also considered to be a largely practical consideration, and that publication of an indicator would be useful even if it was no more than annually.

\section{Existing Indicators of Confidence in Climate Policy}

There are three broad sources of insight into confidence in climate policy that currently exist; (a) survey-based indicators of confidence in specific markets related to the low-carbon transition, (b) the use of price- and value-related changes to 'reveal' changing confidence by proxy, and (c) statements made in corporate carbon-related reporting. This section discusses each of these, and how they inform but differ from a more general measure of confidence in climate policy.

\subsection{Survey-based Indicators of Confidence in Low-Carbon Related Markets}

Surveys of confidence in carbon markets (tradable permits) are a clear, direct indicator of confidence in what is often the core of a climate policy mix (e.g. the EU ETS in the EU). Two key existing surveys measure confidence in carbon markets:

- Point Carbon Thomson Reuters - Carbon Market Survey. This survey is released annually. In 2015 , it received 1,203 responses to 86 questions related to confidence, expectations and consequences of carbon markets around the world (specifically: EU ETS, WCI, RGGI, Chinese Pilot Markets, South Korea, Kazakhstan, New Zealand, CDM and JI). A wide range of actors are requested to participate in the survey (including carbon traders, emitting companies, governments/administration, international organisations and industry federations), however it appears the final sample is fully self-selecting. A number of market-specific questions are posed, including those illustrated in Figure 2 concerning the EU ETS (which presents a trend of responses since 2006) ${ }^{6}$. However, not all questions require answering by each participant.

\footnotetext{
${ }^{6}$ http://petrofed.winwinhosting.net/newsletter/WR-414_22May15/w414_23.pdf
} 


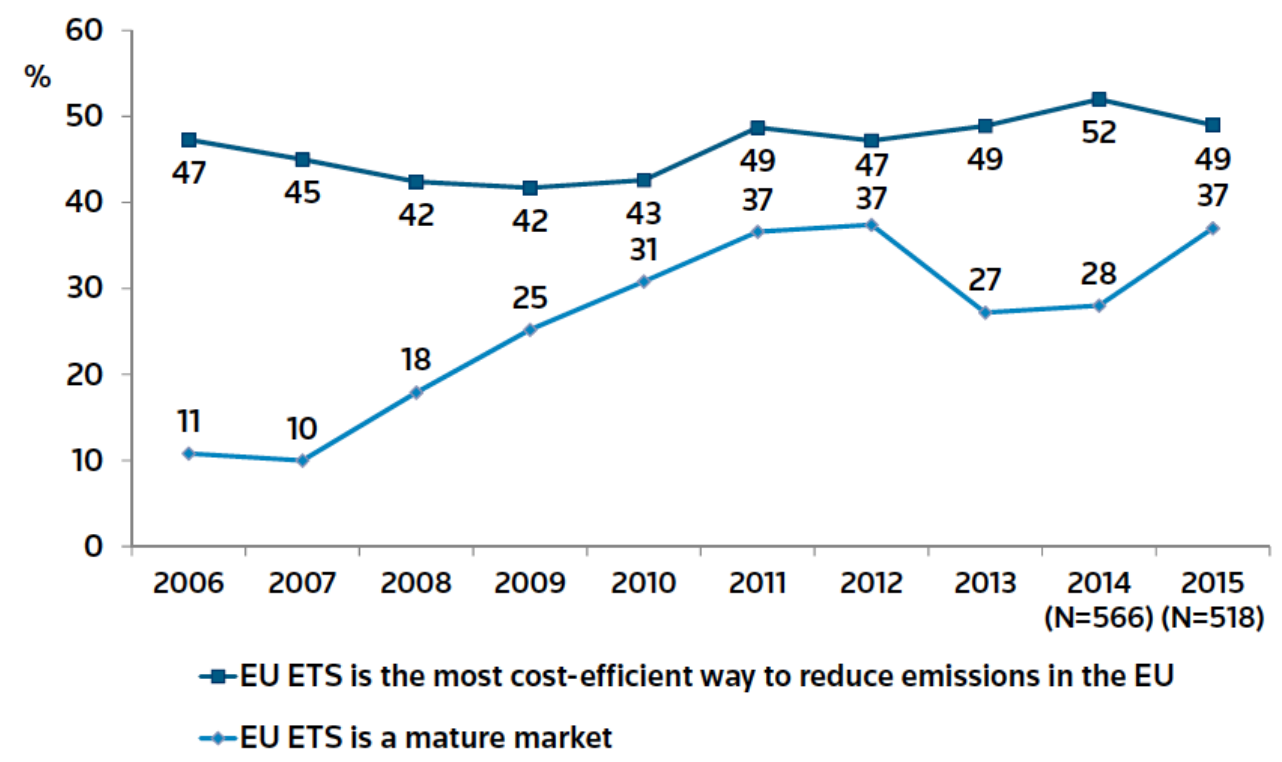

- IETA - GHG Market Sentiment Survey. This survey is designed to assess key dimensions of carbon market sentiment, such as future price and policy expectations, as well as capturing participants' perceptions of the past 12 months and prospects for the future (through 34 multiple choice questions). The survey is conducted amongst IETA (international Emissions Trading Association) members only (including 'all parts of the emissions trading and climate finance industry'), with coverage over 122 respondents in 2015. As with the above survey, actors concerned with tradable permit markets around the world are invited to participate, but participants are ultimately self-selecting (with the majority in the EU). Not all questions must be answered by each participant. Figure 3 illustrates the trend in average long-term price expectations for the EU ETS by participants (for 'Phase III and beyond') ${ }^{7}$.

Figure 3 - Average EUA Price Expectations for Phase III and Beyond over Successive Surveys (IETA GHG Market Sentiment Survey)

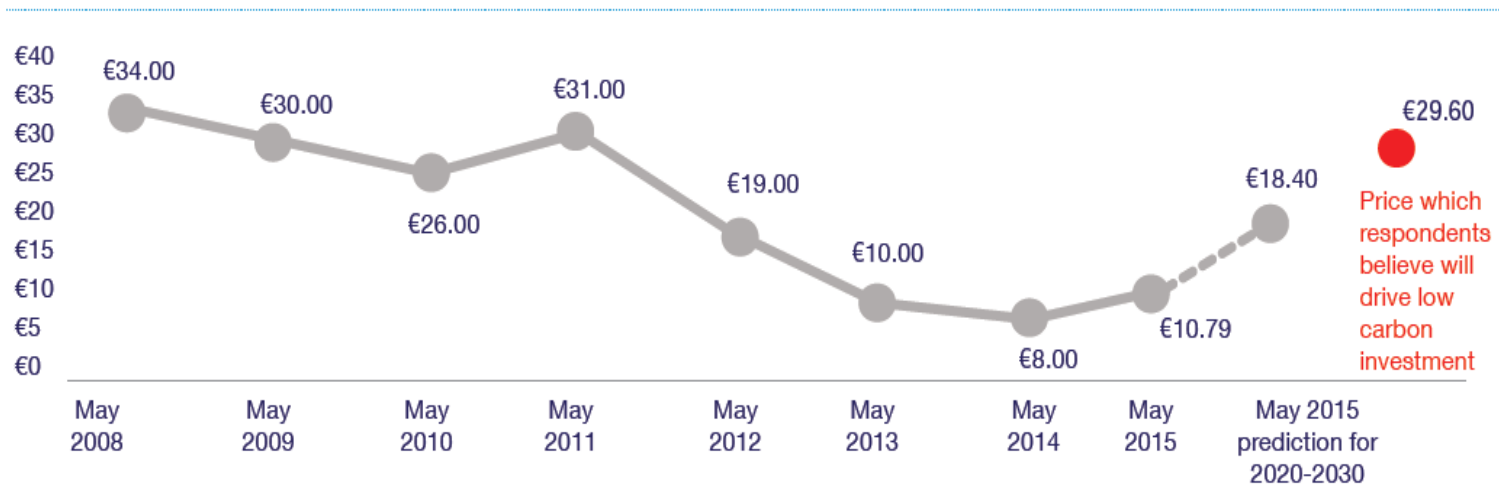

Alongside carbon markets, indices and surveys of confidence in also exist for low-carbon related markets in renewable energy and energy efficiency.

- REA - Renewables Industry Confidence Survey/Index. This was produced by the UK's Renewable Energy Association (REA) with the stated objective of 'capturing the outlook for the renewables industry in relation to turnover, new business and employment. It also takes into account industry's confidence in relevant regulatory regimes, its sentiment about statements on the future direction of policy and its verdict on the likelihood of meeting renewable energy

\footnotetext{
${ }^{7}$ http://www.pwc.co.uk/services/sustainability-climate-change/publications/future-of-carbon-markets-2015-report.html
} 
targets'. The initial intention was to publish an update twice a year, however it seems the survey/index was only published twice (both in 2013). The survey was open to all members of the REA and Solar Trade Association, with 95 (self-selecting) responses received in the second survey (with over half from project developers and consultants). 11 questions were asked concerning 'confidence' levels, with multiple-choice responses ranging from 'very poor' to 'excellent' confidence levels. These responses are averaged and indexed to provide a single 'confidence' value between 1 and $100^{8}$. Figure 4 illustrates the results produced by the second survey conducted in 2013.

Figure 4 - REA Renewables Industry Confidence Survey/Index Results (Q3 2013)

THE RENEWABLES INDUSTRY CONFIDENCE INDEX for 2013 Q3 $=\mathbf{4 8 . 5 \%}$

Renewables Industry Confidence Index 2013 Q3

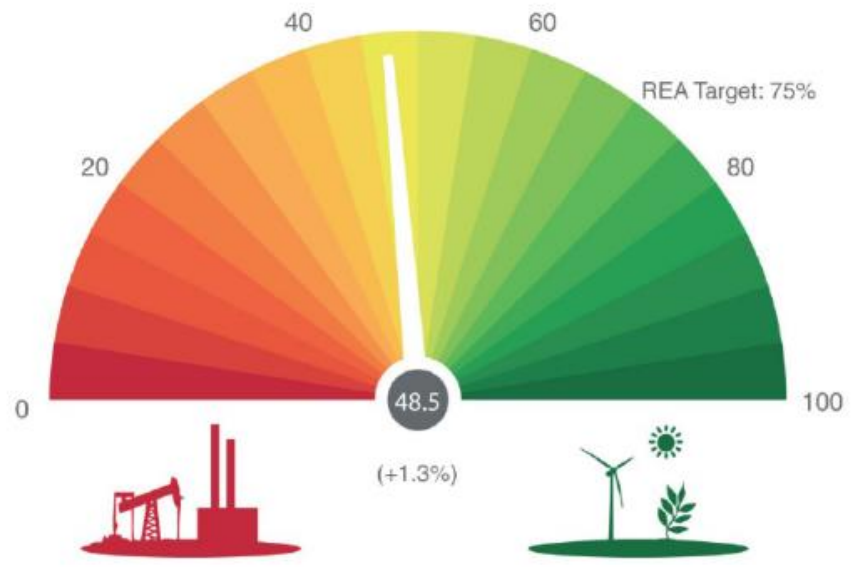

- EY - Renewable Energy Country Attractiveness index (RECAI). Established in 2003, EY's global quarterly publication ranks 40 countries (including the UK) on the 'attractiveness' of their renewable energy investment and deployment opportunities, based on a number of macro, energy market and technology-specific indicators. Figure 5 illustrates the parameters that feed into the Index. Each parameter comprises a series of underlying indicator datasets, each of which are assigned a score out of 5 . Weightings are applied to each parameter and, finally, each driver category, to derive the total RECAI score. Each technology is also allocated a weighting based on the ratio of projected dollar spend over our four-year outlook period. Scoring indicators are based on either publicly available or purchased data, EY analysis or adjustments to third-party data. Some are revised on a quarterly basis while others are updated or benchmarked annually depending on the frequency of data or the nature of the scoring indicator ${ }^{9}$.

\footnotetext{
${ }^{8}$ http://www.r-e-a.net/upload/publications_-_131031_rics_v2_final_report.pdf

${ }^{9}$ http://www.ey.com/GL/en/Industries/Power---Utilities/Renewable-Energy-Country-Attractiveness-Index
} 


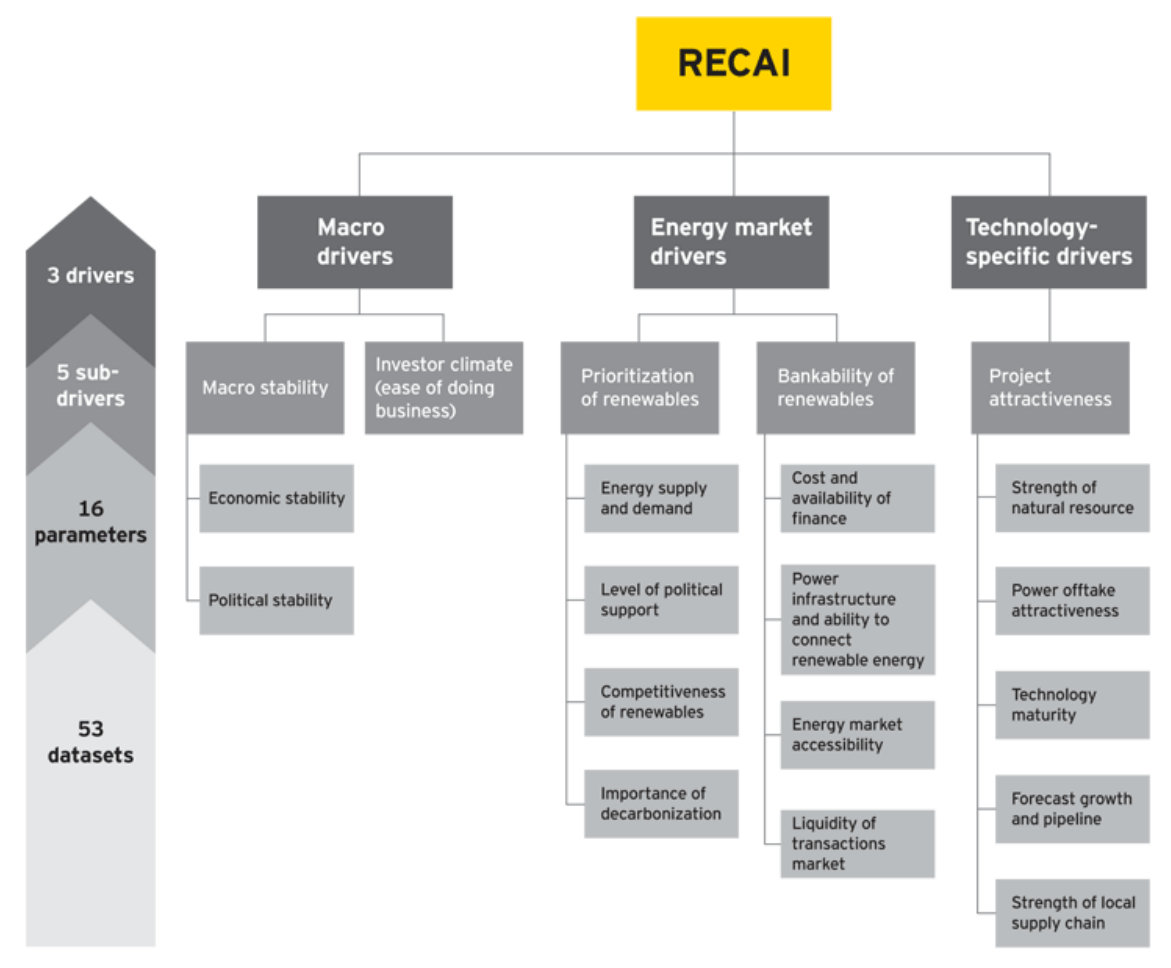

- EEVS - Energy Efficiency Trends Market Monitor. This report, released quarterly since mid-2012, aims to highlight trends in non-domestic energy efficiency in the UK (initially across a range of EU countries until mid-2014). The Monitor received responses from 62 organisations (38 consumer organisations, 24 suppliers) for the Q1 2015 report. It presents an overall industry confidence' index, constructed from weighted confidence indicators concerning orders received from national and overseas customers, number of staff employed, sales prices, and industry views on energy efficiency policy. Figure 6 illustrates the trend over time for this final component. Confidence is measured from -500 (negative), to 500 (positive), with zero being neutral. It is not clear from the report how this index is calculated ${ }^{10}$.

Figure 6 - Trends in Industry Views on Energy Efficiency Policy

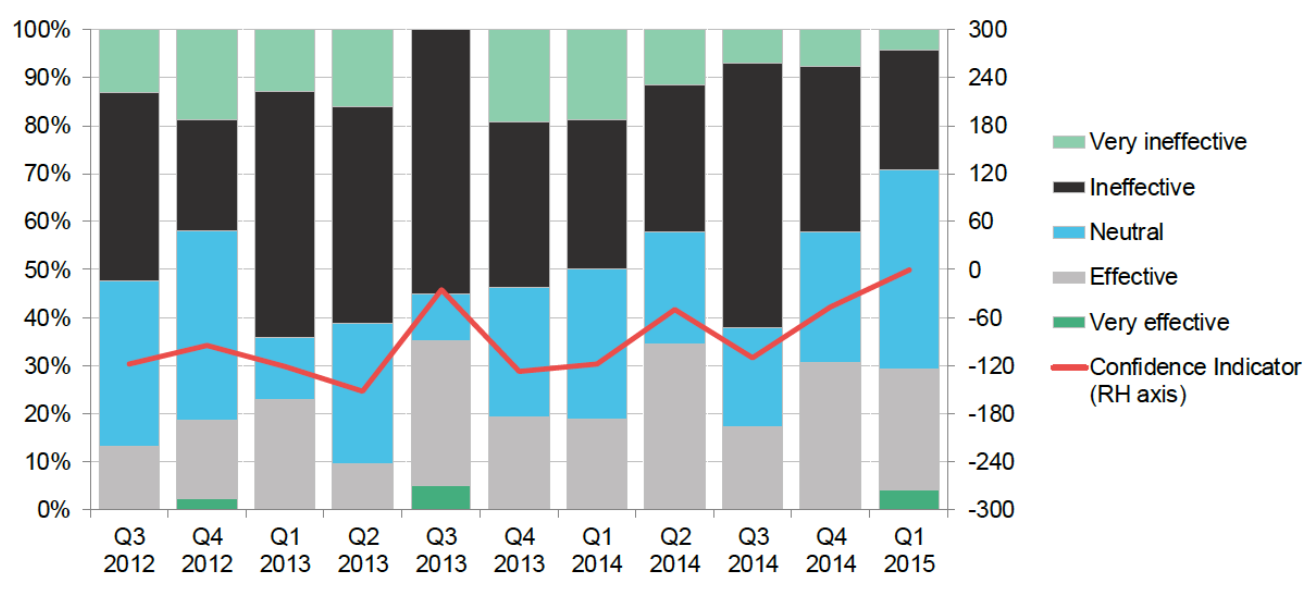

\footnotetext{
${ }^{10} \mathrm{http}: / /$ www.eevs.co.uk/media/trendsq115.pdf
} 
It is clear that none of these indicators quite reflects confidence in climate policy in the manner we seek to explore in this paper. Each of them focus on a specific market only (e.g. carbon markets, renewables and energy efficiency), use (often self-selecting) samples of different sizes and only some actors of relevance, concern varied and often undefined timeframes, and define 'confidence' in slightly different ways (either as the objective of the survey/question, or as a component of a larger indicator).

In May 2015, the campaign organisation The Climate Group launched 'climate policy barometer', designed as a campaign tool in the run-up to Paris 2015 Conference of Parties to the UNFCCC (COP21). The barometer measures 'confidence levels in delivering a strong outcome at COP21 and in global actions toward the low carbon economy'. The barometer is constructed from responses to an (apparently monthly) survey given by a panel of 50 'leaders' selected from The Climate Group's network, including businesses, state and regional governments and international institutions. Results are reported on a percentage basis, and are separated to present confidence of businesses, subnational governments and international organisations separately. The methodology behind the barometer, including the questions asked to participants and how responses are converted into a single percentage value, are unclear. Figure 7 illustrates the trend in results produced between May and September $2015^{11}$

Figure 7 - The Climate Group - Climate Policy Barometer

\section{IS OUR LEADERSHIP NETWORK CONFIDENT THAT THE POLICIES, TECHNOLOGIES AND FINANCING CONDITIONS ARE IN PLACE FOR THEM TO MAKE LONG-TERM LOW CARBON INVESTMENTS?}

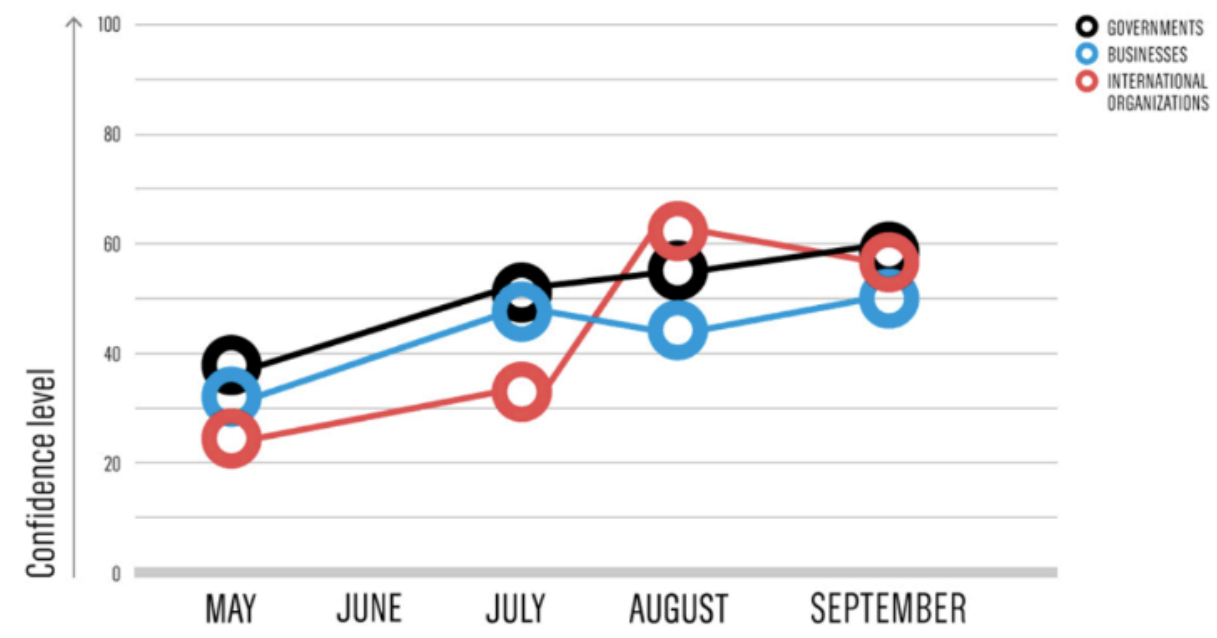

There is also a survey-based measure of policy stringency. The WEF currently collects data on perceived environmental stringency of policies, based on survey data of business executives. This provides one useful approach to measuring sentiment relating to environmental policy, but it does not provide a sense of confidence in future policy, nor is it specific to climate policy.

\footnotetext{
${ }^{11}$ http://www.theclimategroup.org/what-we-do/news-and-blogs/80-of-citizens-see-threats-and-opportunities-of-climatechange-new-global-survey/
} 


\subsection{Proxy Indicators: Prices and Values}

\subsubsection{Carbon Market Futures}

There are a number of futures contracts available in carbon markets, including EUAs (European Union Allowances, for the EU ETS), CERS (Certified Emission Reductions, under the Clean Development Mechanism) and ERUs (Emission Reduction Units, under the Joint Implementation framework). It might be expected that the higher the confidence the market places on an increasingly stringent climate policy framework, the higher the values of these futures.

However, the values buyers place on such futures depends not on the broad direction of climate policy, but more on the specific design of the carbon pricing instrument in question, and the interaction of other instruments with it that may influence price developments in the medium- to long-term. For example, the price for EUA futures depends on confidence in the EU ETS. Stronger Member State action to reduction emissions, such as the introduction of emissions performance standards on power stations or a carbon price floor, might be expected to lower prices for EUAs, despite being an indicator of more committed political action on climate policy. Similarly, expectations about future economic performance have a strong influence on expected future EUA prices, but do not have a simple relationship with policy credibility.

There is thus a difference between more general credibility in the direction of policy-the seriousness with which policymakers are expected to pursue emissions reductions-and the futures prices of carbon allowances within a given market. Indeed, diverging carbon policy confidence and futures prices might provide policymakers with useful information, for example on policy coherence.

\subsubsection{Share Values of 'High-' and 'Low-Carbon' Companies}

An alternative price-based metric is the share price of companies both with significant involvement in high- and low-carbon activities or assets. Clear examples are fossil fuel extracting firms and manufacturers of renewable generation technologies, both of which are clearly significantly impacted by the direction of and political commitment to climate policy.

However, this also presents substantial issues. Firstly, share prices are clearly impacted by nonclimate policy drivers such as, in the case of fossil fuel extraction companies, expectations about future prices, future recoverability of a company's reserves and resources, expectations about global demand, and expectations about future resource discoveries. Isolating the impact of climate policy alone, and in a particular jurisdiction, therefore, is a difficult task. Even if such an effect may be isolated, what this actually represents may still be difficult to determine. For example, share prices of a given company are likely to change in one direction or the other (and by different magnitudes) in response to changes in climate policy depending on both long- and short-term expectations (and actual developments) of both specific instruments (such as feed-in tariffs and carbon pricing), and broad political commitment. Separating the effect of each of these is likely to be a difficult task. Additionally, as with carbon market futures products, such changes rather illustrate the positive or negative effects of such policy and political commitment on the company or sector, rather than 'confidence' per se. 


\subsection{Climate policy risks and opportunities in corporate reporting}

A key example of corporate reporting is responses to annual questionnaires requested by CDP on behalf of investors. The questionnaire is wide ranging ${ }^{12}$, and includes questions relating to perceptions of risk and opportunities surrounding climate change (Questions CC5 and CC6). Respondents are able to respond to this within three categories, the first of which is 'risks/opportunities driven by changes in regulation'. For each risk/opportunity driven by changes in regulation identified, respondents are requested to provide the following information (subject to either standardised or freeform responses):

- A description of the risk/opportunity

- Potential impact

- Timeframe of impact (standardised responses)

- Direct or indirect impact (standardised responses)

- Likelihood (standardised responses)

- Magnitude of impact (standardised responses)

- Estimated financial implications

- Management method

- Cost of management

Figure 8 illustrates the disclosure of regulatory risks and opportunities to reporting firms in the 2015 disclosure, concerning timeframe and likelihood of regulatory change. It suggests that both potential risks and opportunities are greatest in the short term. In all cases, regulatory changes (regardless of the specifics), are anticipated to be overwhelmingly at least 'more likely than not'.

Figure 8 - Climate Policy Regulatory Risk and Opportunities - CDP 2015 Disclosure

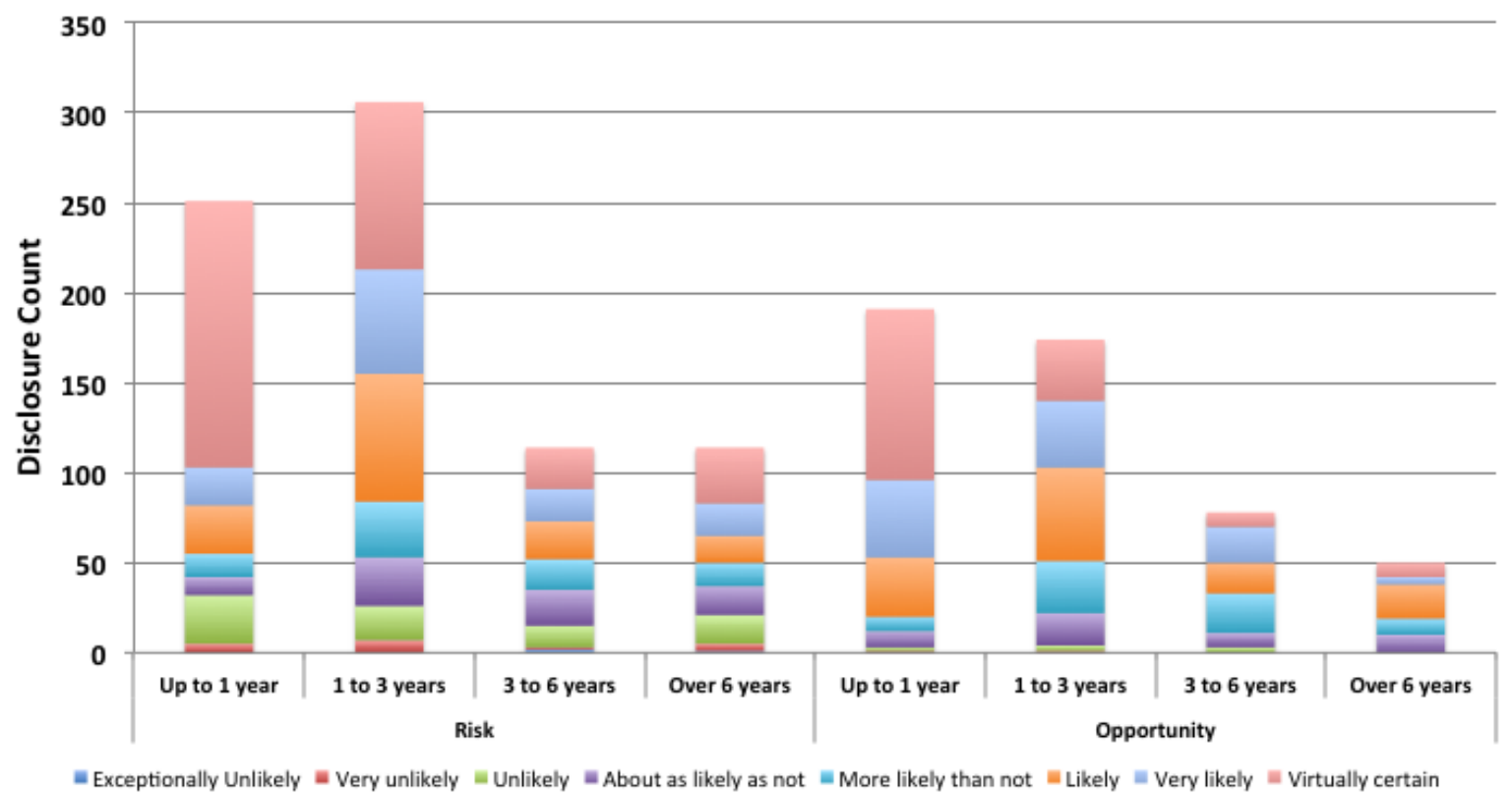

However, there are some clear issues with this data and its use as an indicator for confidence in climate policy. Firstly, the risks and opportunities reported generally refer to specific instruments rather than the general direction of travel. Secondly, firms report the risks and opportunities of changes in climate policy to their operations, which is clearly not the same as confidence in

\footnotetext{
${ }^{12}$ For the 2015 questionnaire, see: https://www.cdp.net/CDP\%20Questionaire\%20Documents/CDP-climate-changeinformation-request-2015.pdf
} 
commitment to decarbonisation. Additionally, firms are much more likely to report on policy changes they believe have at least a reasonable chance of happening, rather than all potential changes in policy that may occur (either positively or negatively from their perspective). Confidence (or belief) that government(s) is doing something that might, a priori, be expected to be similar across firms in different sectors; whereas the exposure of different sectors to climate policy is clearly different. For example, some (particularly carbon-intensive) firms would see a strong policy framework as a substantial risk to their business.

\section{Lessons from broader (non-climate specific) efforts to measure 'confidence' and 'uncertainty'}

\subsection{Methods used in business and consumer confidence indices}

In the UK, trends in the Primary Consumer Sentiment Index (PCSI) and UK Business Confidence Monitor Report (BCMR) are both widely believed to be closely related to consumer spending and business investment (although there is some debate about the specific nature of the relationship, and exactly what is meant by, for example, 'consumer confidence' ${ }^{13}$ ). The correlation with observed trends gives such indicators of confidence some obvious usefulness and credibility. Collecting this data requires surveys. The poll approaches used by Thompson Reuters/Ipsos and ICAEW/Grant Thornton to compile the PCSI and BCMR, respectively, are rather simple.

For the PCSI, a national representative sample of 1,000+ adults are surveyed on a monthly basis with eleven questions, such as 'Now, thinking about our economic situation, how would you describe the current economic situation in Great Britain? Is it... very good, somewhat good, somewhat bad or very bad?', and 'Looking ahead six months from now, do you expect your personal financial situation to be much stronger, somewhat stronger, about the same, somewhat weaker, or much weaker than it is now? ${ }^{14}$. Questions and responses are weighted and combined to form the PCSI (published monthly). The BCMR is even simpler. The results of around 1,000 responses by ICAEW (Institute of Chartered Accountants in England and Wales) members in industry and commerce sectors to the question: "Overall, how would you describe your confidence in the economic prospects facing your business over the next 12 months, compared to the previous 12 months?'. Five responses are possible, ranging from 'much less confident' to 'much more confident', with each given a score from -100 to +100 (with intervals of 50 ). Responses are then weighted by regional location, size and sector of the respondant to produce the final BCMR (published quarterly) ${ }^{15}$.

The European Commission has produced a 'best practice' guide on business/consumer sentiment sampling ${ }^{16}$, along with a manual for the programme of harmonised sentiment surveying ${ }^{17}$. These provide some guidance on how to achieve reliable data from such surveys, and is a useful source of information in thinking about a sampling strategy for a policy-focused sentiment survey.

\footnotetext{
${ }^{13}$ Berry and Davey 2004, How should we think about consumer confidence? Bank of England Quarterly Bulletin, Autumn.

${ }^{14}$ https://www.ipsos-mori.com/Assets/Docs/Polls/thompson-reuters-pcsi-september-2015.pdf

${ }^{15}$ http://www.icaew.com/ /media/corporate/files/about\%20icaew/what\%20we\%20do/business\%20confidence\%20monit or/2015/bcm_q3_15_appendix.ashx

${ }^{16}$ http://ec.europa.eu/economy finance/db indicators/surveys/documents/bcs best practice en.pdf. See also numerous related methodological and conceptual documents on sentiment surveying of both business and consumers here: http://ec.europa.eu/economy finance/db indicators/surveys/index en.htm

${ }^{17} \mathrm{http}$ ://ec.europa.eu/economy finance/db indicators/surveys/documents/bcs user guide en.pdf
} 


\subsection{Index of Economic Policy Uncertainty}

A relatively recent development, produced by Baker et al $(2013)^{18}$, is the concept of an index of 'Economic Policy Uncertainty' (EPU). The index is built on three weighted components; the frequency of newspaper references to economic policy uncertainty, the number of (US) federal tax code provisions set to expire, and the extent of forecaster disagreement over future inflation and government purchases.

Baker et al (2013) test their concept for the USA. Newspaper references to economic policy uncertainty is examined by performing month-to-month searches of ten major newspapers in the USA for key search terms including 'uncertainty' or 'uncertain', with the terms 'economy' or 'economic', and one or more of a range of other key terms such as 'deficit' or 'legislation'. As such, an article must contain reference to uncertainty, the economy and policy. Economic forecaster disagreement, which when significant would indicate increased uncertainty, draws on the quarterly Federal Reserve Bank of Philadelphia's Survey of Professional Forecasters (SPF), which collates forecaster projections for a range of macroeconomic variables for the following five quarters, including Consumer Price Index, purchases of goods and services by state and local government, and purchases of goods and services by federal government). Dispersion in forecasts for these variables for one year in the future is taken into account, as they are directly influenced by monetary and fiscal policy decisions. These two factors, along with tax code expiration data, are normalised and weighted to produce a single index. Figure 9 illustrates the (monthly) EPU index for the USA for 1985 to 2014 , produced by Baker et al $(2015)^{19}$, and indicates that the index may be reasonably correlated to 'shocks' to the economic system. An index based on the Baker et al (2013) has also been used by the European Commission ${ }^{20}$.

Figure 9 - Economic Policy Uncertainty Index USA - 1985-2014

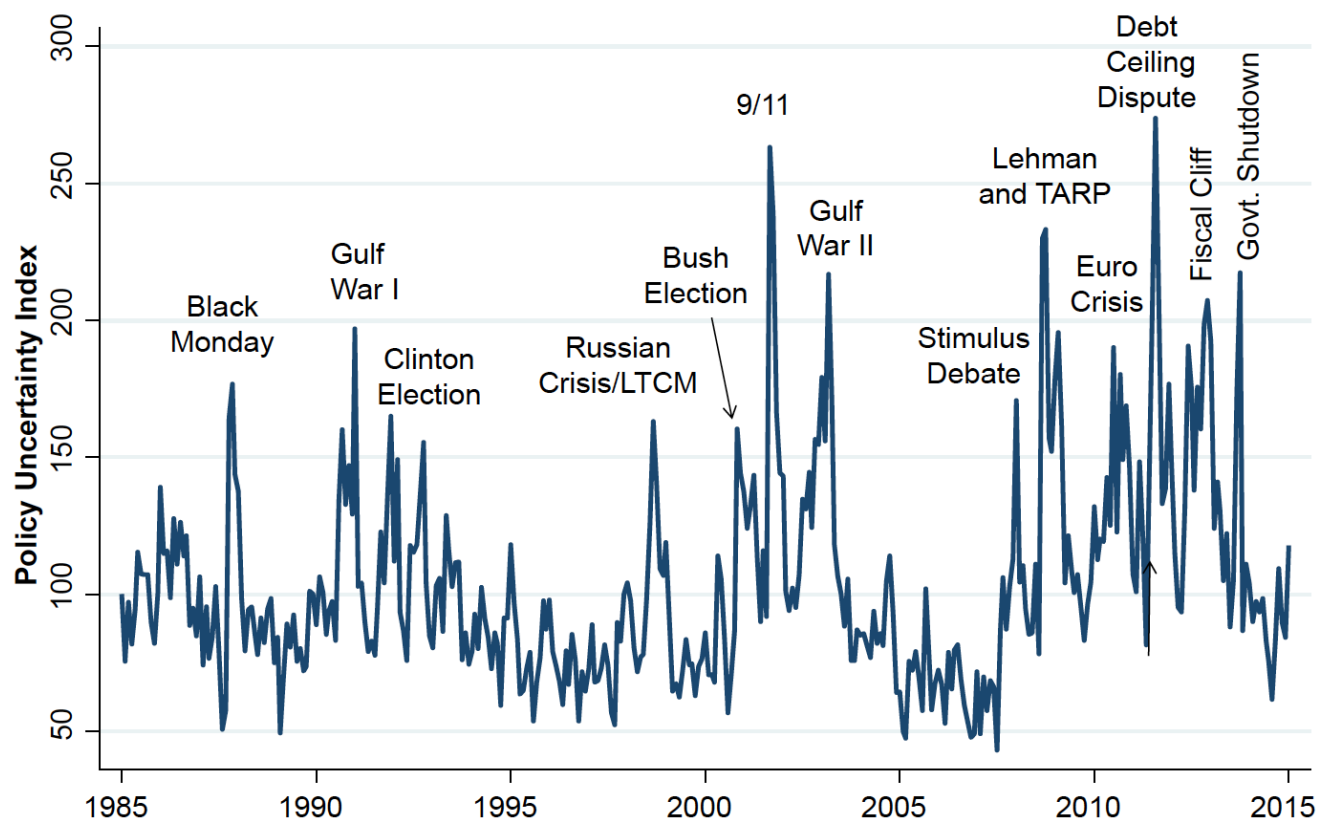

\footnotetext{
${ }^{18}$ Baker, S.R. Bloom, N., Davis, S.J. (2013). Measuring economic policy uncertainty. Chicago Booth Working Paper 83

${ }^{19}$ Baker, S.R., Bloom, N., Davis, S.J. (2015) Measuring Economy Policy Uncertainty, NBER Working Paper 21633

${ }^{20} \mathrm{http}$ ://ec.europa.eu/economy finance/db indicators/surveys/documents/workshops/2014/ecb a.gieseck mb1310 box uncertainty.pdf
} 


\section{Summary - Options for a Climate Policy Confidence Indicator}

Various options exist for defining the parameters of a climate policy confidence indicator to satisfy, to different extents, the three aims of such a tool (political pressure to maintain commitment to decarbonisation, research on the determinants of confidence and research on the impact of confidence on other variables).

Determining confidence in climate policy is only likely to be useful (or possible) amongst those who are aware of climate policy in the first place. This is likely to include particular firms and sectors with particularly high-carbon activities, that produce high-carbon products or services, or those that rely on strong climate policy in order to grow. However, individual actors such as householders are unlikely to be aware of climate policy frameworks, despite cumulatively producing a substantial proportion of emissions. Determining confidence amongst a defined low-carbon sector, such as the groups presented in Table 1, may focus effort and prevent allow direct or indirect inclusion of most sectors of relevance. As each of the different levels of climate policy governance and timeframes have different direct and indirect implications for investment and behavioural decisions, an indicator that considers at least key differences in spatial and temporal distinction is likely to be required. This may be national and international policy direction and commitment, and a 'short-', 'medium-' and 'long-term' timeframes (however specifically defined). In order to satisfy each of the three aims of the indicator, a monthly or quarterly publication would likely be preferable.

As is clear from the discussion above, there are three broad approaches for constructing and populating climate policy confidence indicator.

\subsubsection{Survey-based approach}

A survey-based approach would need to be designed carefully, with an appropriate sampling strategy and a clear definition of both the construct (climate policy 'confidence') and the population of interest (e.g. low-carbon economic sectors). The implications of potential respondent bias and sampling bias would need to be carefully addressed. Appropriate questions might include the following:

1. 'Do you expect (national/global) climate policy to be become more stronger or weaker over the next year, five years and ten years?' (Five possible answers, from 'much stronger' to 'much weaker').

2. 'Are your investment intentions (including R\&D) likely to be influenced climate policies over the next year, five years or ten years?' (Five possible answers - 'Absolutely' to 'Absolutely not').

3. Do you expect your investments in low-carbon goods and services (and R\&D) to change against existing levels? (Five possible answers - 'Significant increase' to 'Significant decrease').

Answers may then be weighted and normalised to produce a single (perhaps numerical) indicator. The key advantage of a survey-based approach is that it attempts to directly measure subjective perceptions, which is the focus of the proposed indicator. The disadvantages are the relatively higher cost, and long project time commitment required to secure a good time series, along with potential self-selection of participants.

\subsubsection{Text-analytic approaches}

An alternative to a survey-based approach is one using text analytics, as used by Baker et al (2013) to measure economic policy uncertainty. Using this kind of approach would have two potential benefits. It would be lower cost, and it may be used retrospectively on historical text sources (newspapers), along for a longer time-series for empirical investigation. The option to use Tweets or other social 
media content could also be explored, as this would potentially offer a means to analyse data over much more fine-grained timescales. Other sources, such as official records of parliamentary debates (e.g. Hansard in the UK), may be another potential option. A weighted basket may allow for a combination of inputs covering divergent approaches. Figure 10 illustrates an example of text analytics applied to nine major UK newspapers, which contain reference to both 'energy policy' and 'uncertainty', or synonyms ${ }^{21}$. The right axis and red line indicate the total count of articles containing these terms between September 2008 and August 2015, whilst the left axis and blue line indicate the number of these articles as a proportion of all articles concerning climate policy (or synonyms).

Figure 10 - Energy Policy Uncertainty in the UK - Text Analytic Example (preliminary results)

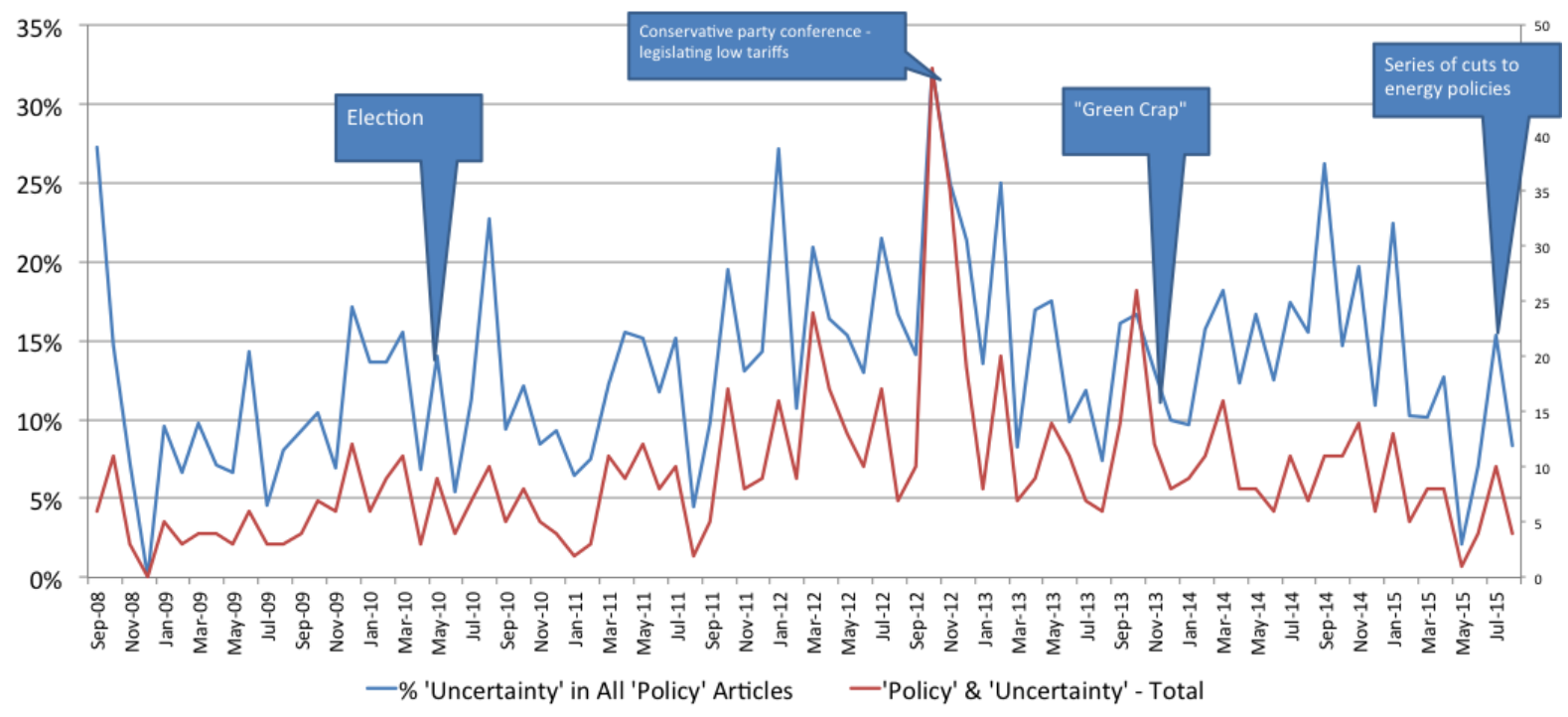

Both trends show relatively substantial variation over time. Although some policy and political events are highlighted in Figure 10, a correlation is not particularly clear. Further work would be needed to refine this initial analysis (including search terms). Additionally, such analysis may (at least initially) require validation against survey data in order to determine its validity.

\subsubsection{Changes to prices and values}

As per the EPU index developed by Baker et al (2013), measuring the magnitude of divergence in forecasts of the value or growth in key economic sectors related to climate policy (rather than the economy as a whole), may act as an effective proxy for confidence in climate policy. As above, such key sectors could be defined as those presented in Table 1. However, unlike forecasts of growth of the economy as a whole, existing projections for growth of the low-carbon economy are few and far between (particularly of the same definition). As such, the usefulness of such an approach may be limited in practice.

Another approach may be to monitor changes in key high- and low-carbon investment indices, such as the Environmental Tracking low-carbon and fossil free indices ${ }^{22}$. However, changes in such an index (as with changes to and differences in projections for low-carbon sector growth), does not

\footnotetext{
${ }^{21}$ Search terms employed were ("energy policy" OR "DECC" OR "Department of energy and climate change" OR "renewables policy" OR "nuclear policy") AND ("uncertainty" OR “uncertain" OR "disarray" OR "confused" OR "confusion" OR "confusing" OR "muddle").

${ }^{22}$ http://etindex.com/
} 
necessarily reflect changes in policy or political commitment. Instead, it may reflect (for example), changes in fossil fuel prices, and thus the relative value of low-carbon options and firms.

\section{Insights from the workshop}

Both surveys and text-based approaches were seen as viable and mutually supportive, but with surveys being seen as better able to uncover key differences among sectors, regions and timescales.

Several participants were interested in the analogy with the Baker et al. indicator ${ }^{1}$, and suggested that the team examine the possibilities of building indicators based on actual policy developments (such as approaching targets with no clarity about longer-term policies; or approaching 'sunsets' on particular initiatives or policies).

\section{Conclusions}

The ease of attracting people to participate in the workshop, and the substantive discussion at the workshop, demonstrated clear interest and enthusiasm for the underlying idea. The process has resulted in a number of follow-up initiatives and potential next steps. Participants all expressed a willingness and interest in being involved further, with some specifically noting interest in collaboration in the preparation of applications for funding, or acting as members of an advisory board for such a bid.

\section{Workshop Participants}

- Will McDowall, UCL Institute for Sustainable Resources

- Dimitri Zenghelis, GRI LSE

- Paul Drummond, UCL Institute for Sustainable Resources

- Sean Kidney, Climate Bonds

- $\quad$ Ruth Prior, CDP

- Samuela Bassi, GRI LSE

- James Evans, Office of National Statistics

- Mike Clarke, Russell Investments

- Gerrard Derricks, University of Oxford

- Angela Francis, Green Alliance

- Matthew Winning, UCL Energy Institute

- Eleanore Arcese, Climate Strategies 


\section{Annex: slides presented at the workshop}

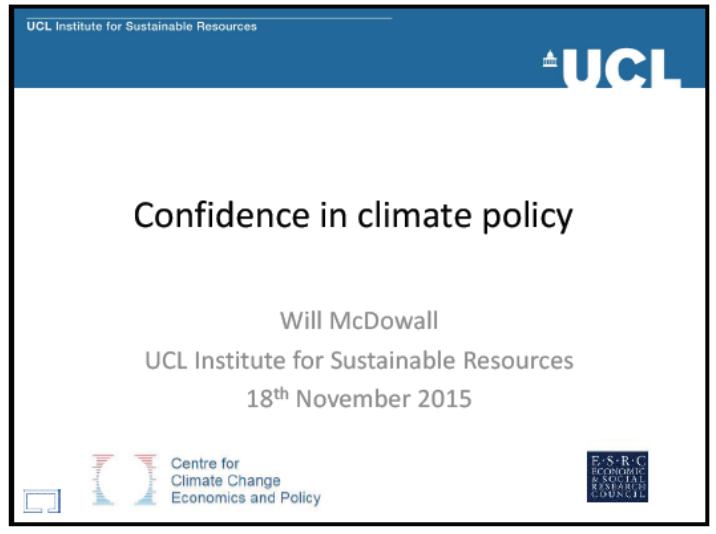

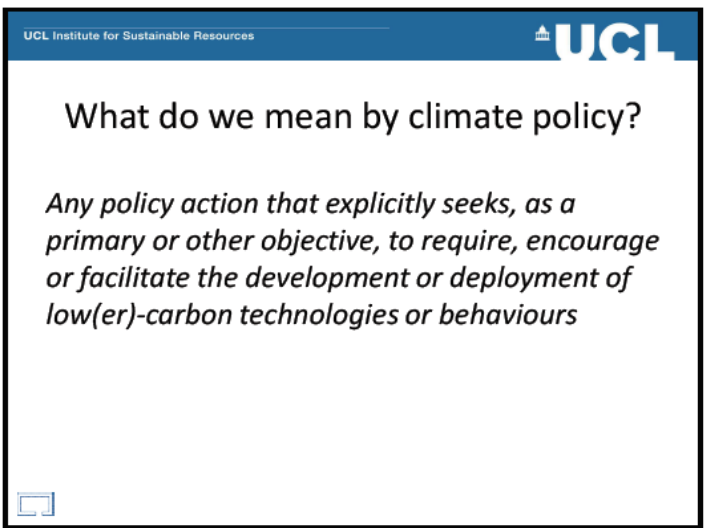

OcL institute for Sustanable Resourcos
Overview
- Objectives \& definitions
- Scope issues
- Existing partial measures of confidence in
climate policy
- Measures of policy confidence in other fields
$\square$

What do we mean by confidence?
- Confidence in ongoing political commitment
to decarbonisation
- Confidence in the continuation (and furtheble fesources
development) of specific policy instruments

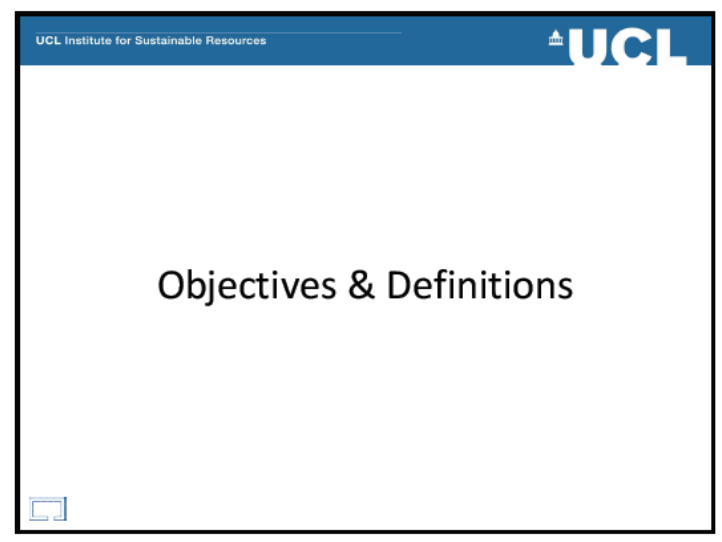

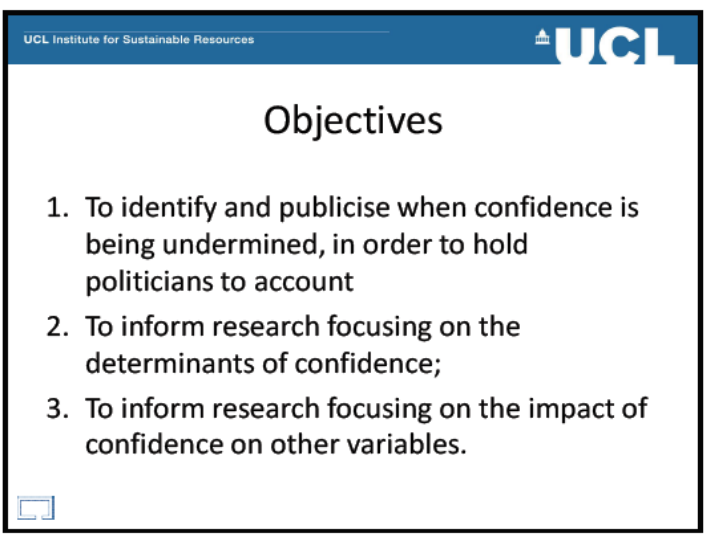




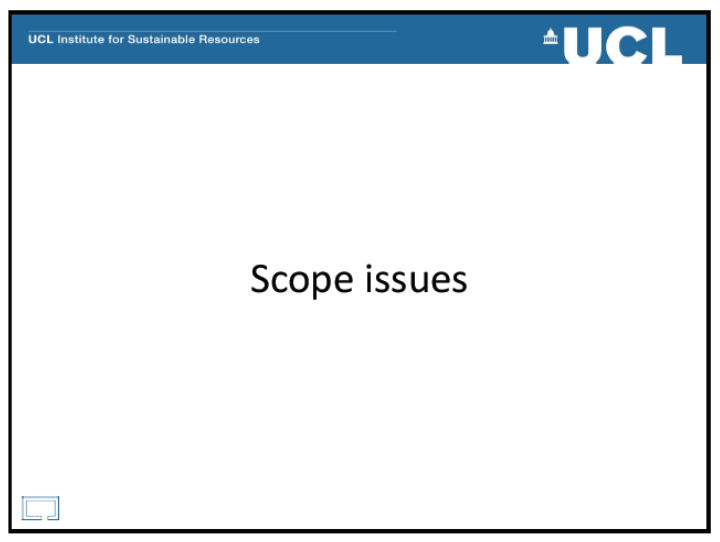

\begin{tabular}{l} 
Four key issues \\
- Sectoral scope: whose confitute tron sustainable nesources \\
- Geographic scope: whose policy matters? \\
- Temporal scope: does long-term vs. short- \\
term matter more? \\
- Periodicity: how often should the indicator be \\
published? \\
\hline
\end{tabular}
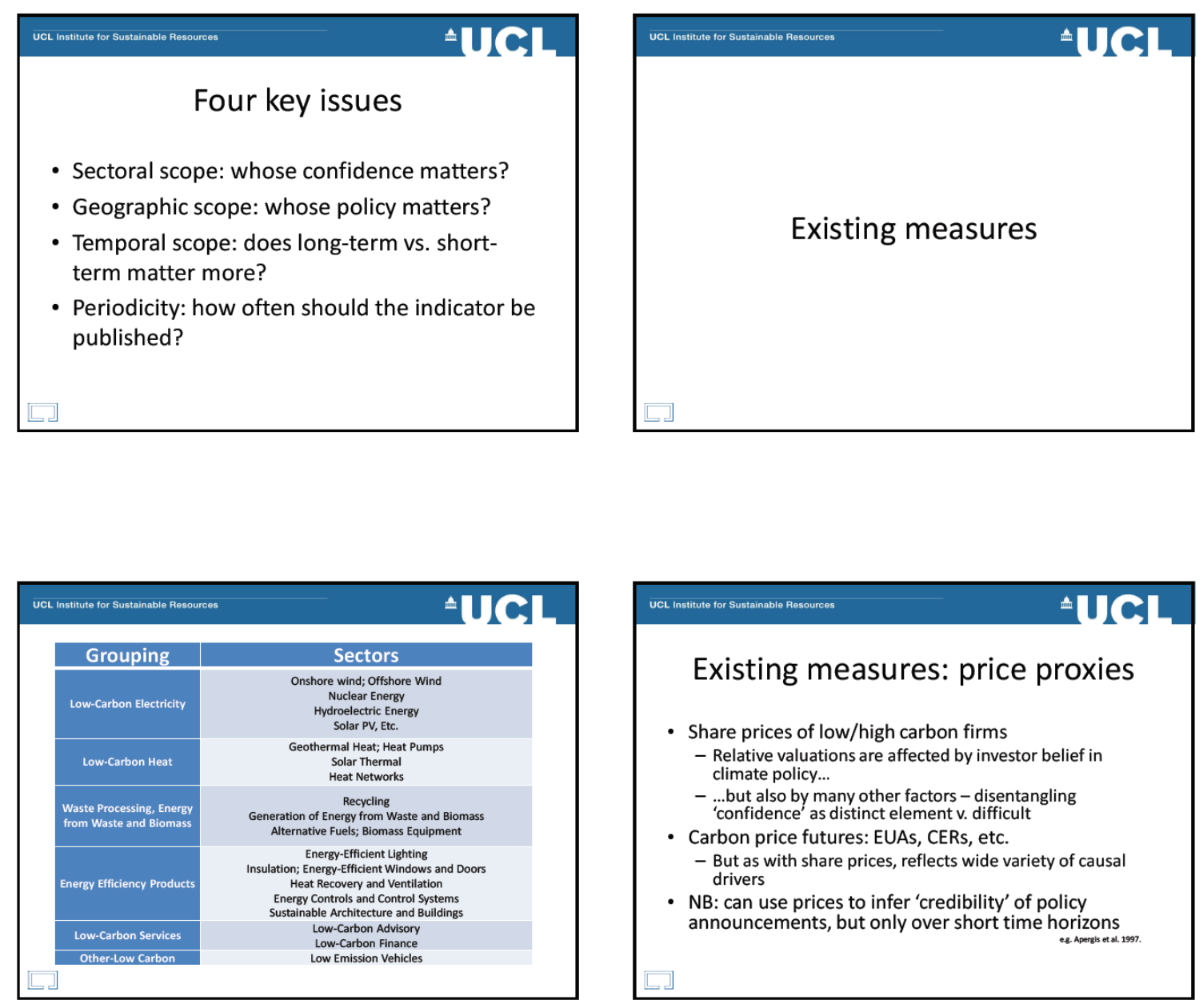

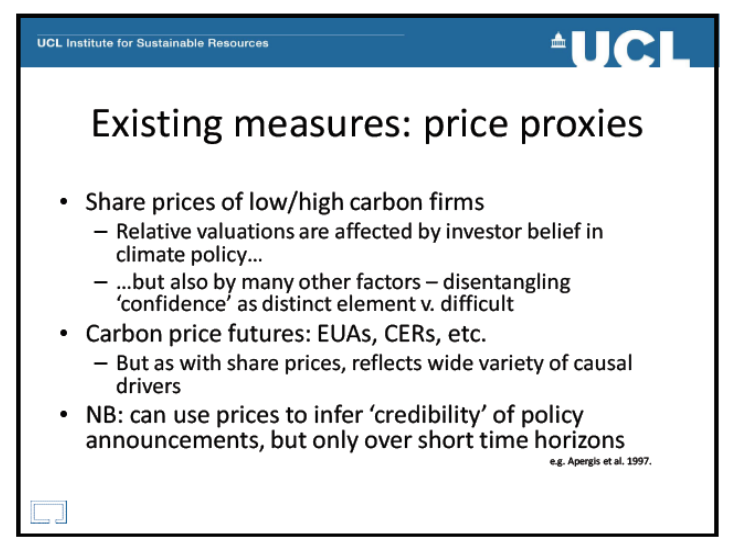



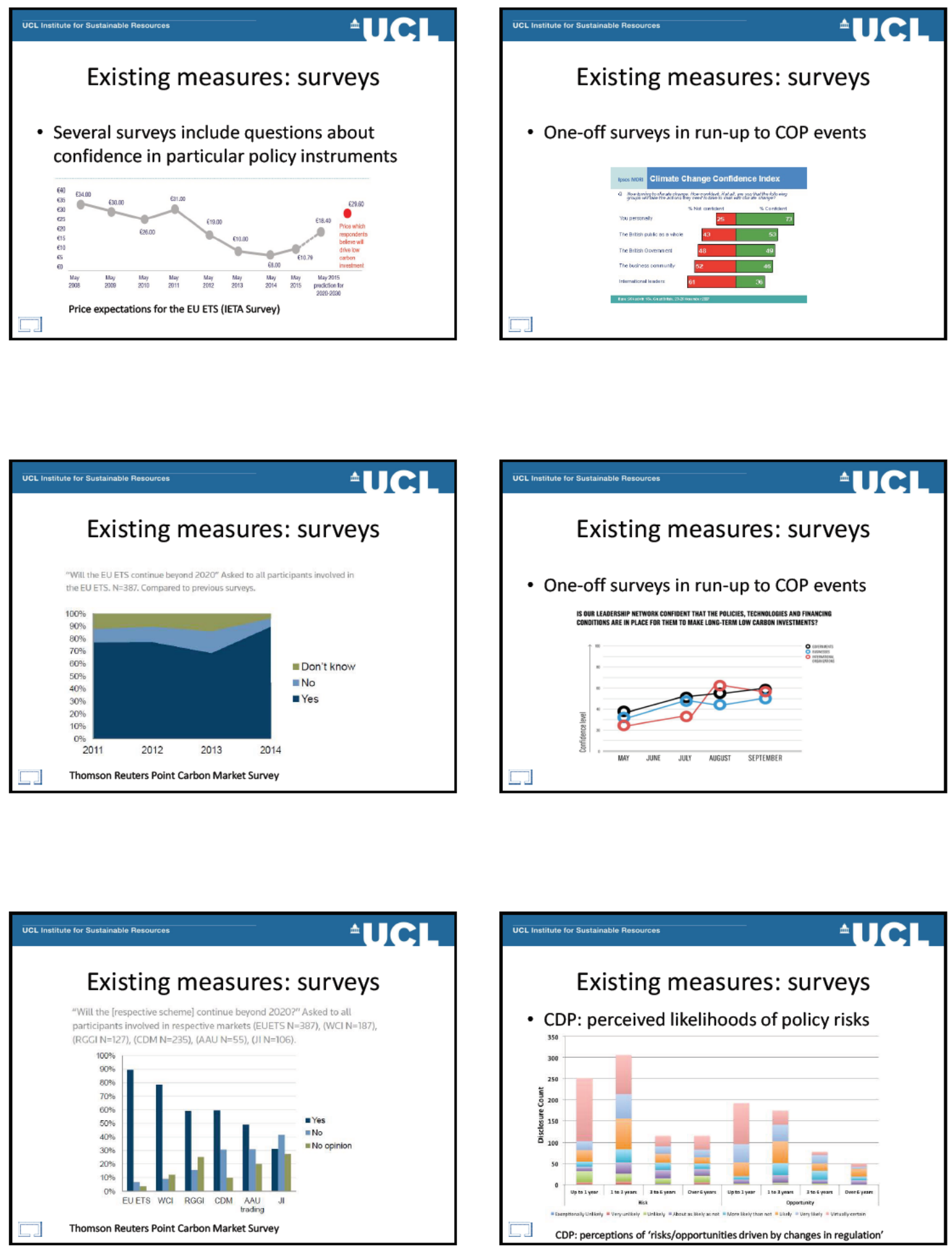

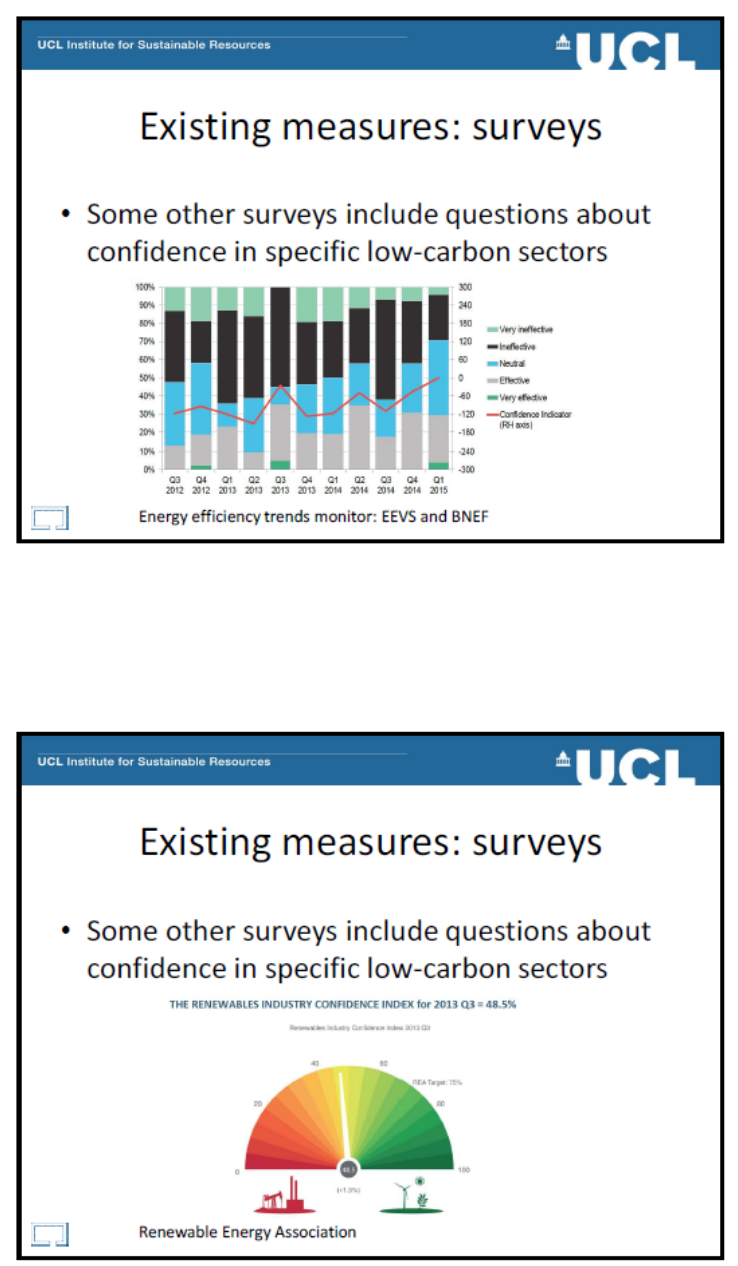

EcL nasitute for Sustanable Resources
Economic Policy Uncertainty Index
- Nee elements in the original index (Baker, Eloom \& Davis)
- Forecaster disagreement
- Number of federal tax code provisions set to
expire

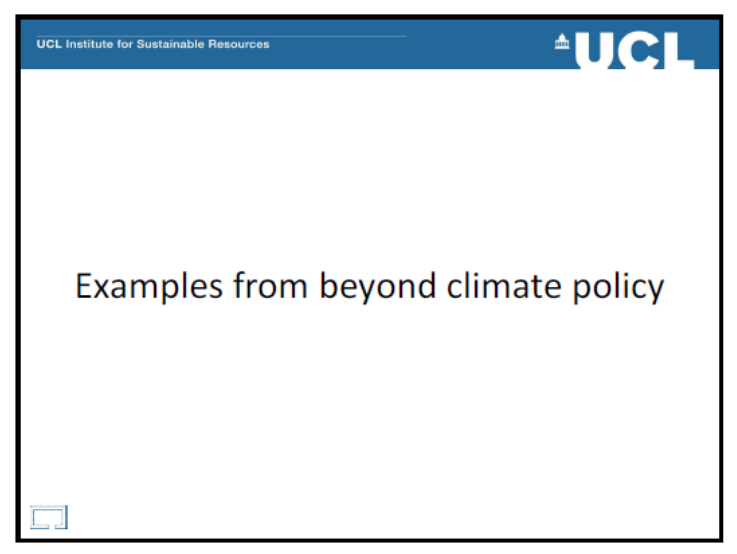




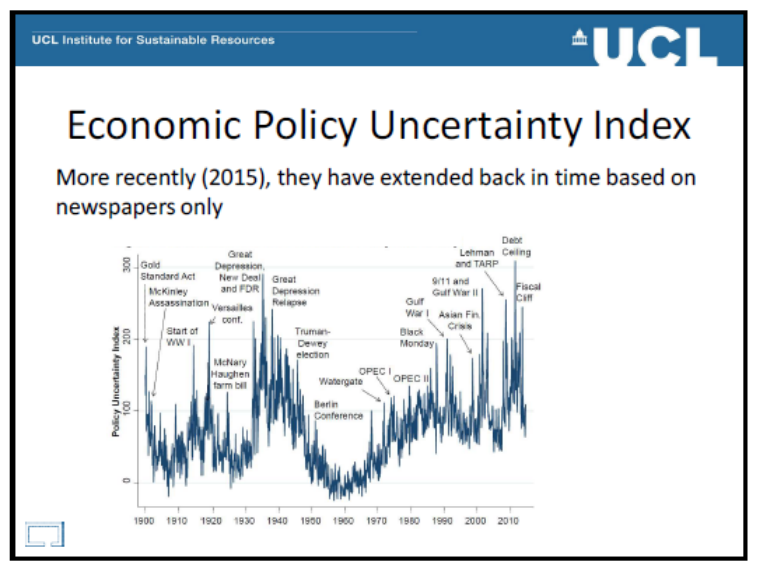

Today's discussion
- Definitions \& objectives
- Scope issues:
- Sectoral: whose confidence?
- Geographatainate Resourcos
- Timeframe: whose policy?
- Periodicity: what frequency of publication is required?
- Existing measures, methods
- Potential partnerships

Occ nastitute for sustanabile Aesourcos
Options for developing a climate policy
indicator
- Advantages: more direct approach to
measuring subjective confidence
- Disadvantages: short time series (or
potentially large cost to develop longer time
series).

